\title{
Factors affecting the impact of covariate adjustment for binary outcomes in randomised clinical trials (RCTS): a simulation study
}

\author{
Ly-Mee Yu*, Douglas G Altman \\ From 3rd International Clinical Trials Methodology Conference \\ Glasgow, UK. 16-17 November 2015
}

There is lack of consensus on whether analysis of RCT data should adjust for important baseline covariates. For binary outcomes, the estimated treatment effect can differ when logistic regression is carried out, even when the covariates are balanced between treatment groups. Simulation studies for RCTs with binary outcomes have shown that adjusting for a single baseline prognostic covariate increases the power to detect treatment effects. The impact on the size of the treatment effect was only notable when a strong prognostic covariate was included. The impact of adjustment for two covariates with different prognostic strengths and directions of the prognostic relationship to the outcome is not known. We present a detailed examination of factors affecting the impact of adjusted analysis. In particular, an adjusted logistic regression model with two covariates ( 1 continuous and 1 binary) are considered simultaneously. The simulation study addresses different levels of event rate and treatment effect, different distributions for the binary and continuous variables, variable prognostic strength of the covariates, and correlation between covariates. These simulations suggest that adjustment will only have a notable effect in extreme scenarios such as, treatment effect is very large and covariates are highly prognostic. We found that the relative difference between the unadjusted and adjusted odds ratios could be larger than $50 \%$, though only under these scenarios. Otherwise the impact of adjustment is small.

Published: 16 November 2015

University of Oxford, Oxford, UK creativecommons.org/licenses/by/4.0), which permits unrestricted use, distribution, and reproduction in any medium, provided the original work is properly cited. The Creative Commons Public Domain Dedication waiver (http://creativecommons.org/publicdomain/ zero/1.0/) applies to the data made available in this article, unless otherwise stated.
doi:10.1186/1745-6215-16-S2-P155

Cite this article as: Yu and Altman: Factors affecting the impact of covariate adjustment for binary outcomes in randomised clinical trials (RCTS): a simulation study. Trials 2015 16(Suppl 2):P155.

Submit your next manuscript to BioMed Central and take full advantage of:

- Convenient online submission

- No space constraints or color figure charges

- Immediate publication on acceptance

- Inclusion in PubMed, CAS, Scopus and Google Scholar

- Research which is freely available for redistribution
- Thorough peer review 